\title{
Determination of IPTG in Recombinant Human Growth Hormone with Ion Chromatography and Pulsed Electrochemical Detection
}

\author{
Wang $\mathrm{L}^{1^{*}}$ and $\operatorname{Lin} \mathrm{B}^{2}$ \\ ${ }^{1}$ Center of Analysis and Measurement, Fudan University, Shanghai 200433, China \\ 2Shanghai Zhangjiang Bio-Tech Co. Ltd, Shanghai 201203, China
}

"Corresponding author: Wang L, Center of Analysis and Measurement, Fudan University, Shanghai 200433, China, Tel: +86 2165643002; Fax: +86 2165643014; Email: lilywang@fudan.edu.cn

Received date: September 11, 2017, Accepted date: September 19, 2017, Published date: September 23, 2017

Copyright: (C) 2017 Wang, et al. This is an open-access article distributed under the terms of the Creative Commons Attribution License, which permits unrestricted use, distribution, and reproduction in any medium, provided the original author and source are credited.

\begin{abstract}
A novel method for the determination of isopropyl- $\beta$-D-thiogalactopyranoside (IPTG), a sulfur-containing compound, a pharmaceutical additive in commercial recombinant human growth hormone (rhGH), has been developed using pulsed electrochemical detection (PED), following ion Chromatographic separation. A Dionex-500 ion chromatograph coupled with an electrochemical detector was employed, equipped with a gold working electrode and an Acclaim 300 analytical $\mathrm{C} 18$ column, with a mobile phase consisting of sodium acetate (NaOAc) buffer ( $\mathrm{pH}$ $5.45,0.01 \mathrm{~mol} / \mathrm{L})$ and acetonitrile $(\mathrm{ACN})(90 / 10$, v/v). Upon optimization, IPTG was found to have a limit of detection of $1 \mathrm{ng} / \mathrm{mL}(0.1 \mu \mathrm{mol})$ with $25 \mathrm{uL}$ injection volume. This method was successfully applied to the determination of IPTG in rhGH samples with the characteristics of simplicity, high sensitivity and good repeatability.
\end{abstract}

Keywords: Ion chromatograph; Pulsed electrochemical detection; Isopropyl $\beta$-D-thiogalactopyranoside

\section{Introduction}

Human growth hormone (hGH) consists of 191 amino acid residues folded into a four-helix bundle structure with two disulfide bridges, with a wide range of biological functions as protein synthesis, cell proliferation and metabolism [1,2]. Recombinant human growth hormone (rhGH) is a type of $\mathrm{GH}$ produced by recombinant DNA technology identical to human growth hormone $[3,4]$.

Isopropyl- $\beta$-D-thiogalactopyranoside (IPTG) as a highly stable molecular biology reagent and a molecular mimic of allolactose to trigger the transcription of the lac operon, is commonly used in cloning procedures to induce the expression of cloned genes which are under the control of the lac operon $[5,6]$. In the thioether group of IPTG (Figure 1), the sulfur atom creates a chemical bond which is non-hydrolysable by the cell, preventing the cell from degrading the inductant. IPTG has also been widely used in the recombinant processing of rhGH $[7,8]$. However, the toxicity of IPTG $[9,10]$ restricted the usage of this promoter system, measuring its presence and concentration in the final products is of importance.

Several different techniques have been used for the analysis of thiocompounds [11], such as liquid chromatography, Capillary electrophoresis and HPLC-MS-based methods [12-17], which have attracted much attention in evaluating sulfur-containing compounds because of their good separation and detection ability $[12,13]$. However, for the absence of strong chromophores or luorophores, the determination of thiocompounds with UV $[18,19]$ or luorescence $[20,21]$ methods should be coupled with derivatization.

Over the past decade, ion chromatography (IC), together with pulsed electrochemical detection (PED), has been accepted [21-24] as highly sensitive and selective methods to detect thiols, disulfides. In addition, both reduced and oxidized thiol moieties can be easily detected without the need of derivatization [12]. Thiocompounds can be detected over a wide range of $\mathrm{pH}$ conditions and the response is relatively unperturbed by buffer composition. Integrated pulsed amperometric detection (IPAD) employs more stable baselines, eliminates oxide-induced artifacts, and yields lower limits of detection than those of other PED waveforms in this method.

In this paper, IC coupled with IPAD was applied to test IPTG in biopharmaceutical hormone rhGH. Electrochemical characterization via cyclic voltammetry was performed to optimize the IPAD waveform, and developed to separate IPTG in rhGH samples and then determine it with PED.

\section{Experimental}

\section{Chemicals, reagents, standard solution and sample preparation}

All solutions were prepared from reagent grade chemicals. HPLC grade sodium acetate $(\mathrm{NaOAc})$ was from Fluka (Steinheim, Germany). HPLC-grade acetonitrile (ACN) was from Fisher Scientific (Fair Lawn, NJ, USA). Mobile phases were filtered with $0.45 \mu \mathrm{M}$ Nylon-66 filters (Fisher Scientific). All solvents were freshly prepared daily with ultrapure grade water (electrical resistivity $18.2 \mathrm{M} \Omega \cdot \mathrm{cm}$ at $25^{\circ} \mathrm{C}$ ).

Isopropyl- $\beta$-D-thiogalactopyranoside (IPTG, high purity grade) was obtained from Calbiochem (San Diego, California, USA) and stored in a refrigerator at $1-5^{\circ} \mathrm{C}$. The samples were placed in plastic microcentrifuge tube (3000 DALTON MWCO, Millipore Corp., Bedford, MA).

\section{Instrumentation}

IC-PED was performed on a Dionex liquid chromatography system (Dionex Corporation, Sunnyvale, CA), equipped with a gold working electrode, an $\mathrm{Ag} / \mathrm{AgCl}$ reference electrode. Solutions were injected with 
an injection valve (Rheodyne, Inc., Cotati, CA) fitted with a $25 \mu \mathrm{L}$ injection loop. Data collection and system control were accomplished using Peaknet software (Dionex, version 5.12) on a Dell OptiPlex Gn computer.

Separation of IPTG was achieved using an Acclaim 300 analytical column, C18, $3 \mu \mathrm{m}$ particle size, $150 \mathrm{~mm} \times 4.6 \mathrm{~mm}$ (Dionex). Unless otherwise specified, the mobile phase solvents were 'solvent $A$ '=sodium acetate (NaOAc) buffer (pH 5.45, $0.01 \mathrm{~mol} / \mathrm{L})$ and 'solvent $\mathrm{B}^{\prime}=$ acetonitrile $(\mathrm{ACN}),(\mathrm{A}: \mathrm{B}=90: 10, \mathrm{v} / \mathrm{v})$, delivered at a flow rate of 1.00 $\mathrm{mL} / \mathrm{min}$. All solvents were filtered, degassed, and kept under N2 (pressure about $68.95 \mathrm{kPa}$ ) at room temperature.

\section{Sample preparation procedure}

The rhGH sample was placed in a $1.5 \mathrm{~mL}$-plastic microcentrifuge tube (3000 DALTON MWCO, Millipore Corp., Bedford, MA). The tube was microcentrifuged (fixed rotor speed $10000 \mathrm{r} / \mathrm{min}$ ) for about $20 \mathrm{~min}$ at $4^{\circ} \mathrm{C}$. After which the supernatant was discarded. A selected residual volume in the tube was weighed and diluted with degassed, deionized water at 1:1000 (v/v). This solution was then filtered through a $0.45 \mu \mathrm{m}$ filter and injected immediately after preparation into the chromatographic system. The same amount of deionized water as the sample was used as blank solution for the same preparation process and analysis.

\section{Results and Discussion}

\section{Electrochemical response and waveform optimization}

Cyclic voltammetry has been performed for the selection of approximate IPAD waveform potentials. The current-potential (i-E) response in $0.01 \mathrm{~mol} / \mathrm{L} \mathrm{pH} 5.45 \mathrm{NaOAc}$ buffer/ACN (90:10, v/v) degassed in the absence and presence of $100 \mathrm{mg} / \mathrm{L}$ IPTG is shown in Figure 2. Under acidic conditions, the residual response displays an anodic peak at about $+1250 \mathrm{mV}$ (wave a in Figure 2) during the forward scan as the formation of surface oxide takes place. On the reverse scan, a cathodic peak at about $+400 \mathrm{mV}$ (wave b in Figure 2) corresponds to dissolution of the surface oxide formed on the forward scan. Breakdown of solvent occurs at about $+1800 \mathrm{mV}$ and $-1000 \mathrm{mV}$, which leads to the generation of $\mathrm{O}_{2}$ and $\mathrm{H}_{2}$ respectively. Reduction of dissolved $\mathrm{O}_{2}$ takes place during both the forward and reverse scans and commences at about $+200 \mathrm{mV}$.

The IPAD waveform has been shown to be effective in electronically rejecting the "background" signal from oxide formation, which is an order of magnitude larger than the signal of the analyte. The detection sequence consists of a series of triangular potential scans to maximize the signal from the transient oxide intermediates of the oxide-catalyzed mechanism. Figure 3 shows the optimized waveform for the detection of IPTG. The waveform starts at a potential lower than that required for oxide formation, scan to a maximum potential that covers oxide formation and analyte, and ends at a potential that is more negative than that required for cathodic dissolution of the formed oxide. The start and end potentials are also more positive than that required for the reduction of dissolved $\mathrm{O}_{2}$. Hence, the contribution to the overall signal from the reduction of dissolved $\mathrm{O}_{2}$ is minimized. On-line degassing as part of the solvent delivery system can relax constraints on the start/end potential [25]. The detection steps in both waveforms are followed by a large negative potential pulse $(-2000 \mathrm{mV}$ for $10 \mathrm{~ms})$ to induce both cathodic cleaning of the electrode [26] and reduce any partly-soluble $\mathrm{Au}$ [27]. This potential pulse is necessary to extend the life of the electrode for months of continuous use. After this, a short positive potential pulse $(+1600 \mathrm{mV}$ for $100 \mathrm{~ms})$ is used to induce anodic cleaning of the electrode. This is followed by $600 \mathrm{~ms}$ at $-200 \mathrm{mV}$ to allow for pre-adsorption of the analyte. The Johnson group has shown that amines can be pre-concentrated 10-fold with the use of an adsorption step in the potential-time waveform. PED at an Au electrode has proven to be selective for sulfur-containing compounds under mildly acidic conditions. The direct electrochemical detection of numerous polar aliphatic compounds is achieved at $\mathrm{Au}$ and $\mathrm{Pt}$ electrodes under the control of multistep potential-time waveforms. In this technique, the waveforms manage the sequential processes of sampling the faradaic signal, from the oxidation of analyte, followed by oxidative cleaning and reductive reactivation of the electrode surfaces [28]. In agreement with these findings, LaCourse and Owens [29] demonstrated that the optimum response for sulfur-containing compounds is obtained by maximizing the time of the adsorption step without negatively affecting the chromatographic integrity of the peaks.

\section{Chromatographic conditions for IC-PAD analysis}

Separation of IPTG was achieved by using an Acclaim 300 C18 analytical column with $0.01 \mathrm{~mol} / \mathrm{L}$ pH $5.45 \mathrm{NaOAc}$ buffer/ACN (90:10, $\mathrm{v} / \mathrm{v})$. The $\mathrm{C} 18$ phases have very high surface coverage, resulting in high capacity. This $\mathrm{C} 18$ column works at a $\mathrm{pH}$ between 2 and 8 . Under such mildly acidic conditions, PED at am Au electrode has proven to be selective for sulfur-containing compounds [29-34]. In LaCourse's work, $\mathrm{PED}$ at $\mathrm{pH} 4.54$ is specific to the detection of the sulfurcontaining compounds IPTG. We studied the $\mathrm{pH}$ value of the buffer solution over the range 4-6 and found that the separation (determination) peak of IPTG is slightly variable in these mobile phases. At pH 5.45, IPTG was well separated and the corresponding response was highly sensitive. Therefore, the $\mathrm{pH} 5.45$ phosphate buffer was chosen as the mobile phase. Figure 4 shows the chromatograms of IPTG standard in $0.01 \mathrm{~mol} / \mathrm{L} \mathrm{NaOAc}$ buffers at $\mathrm{pH} 5.45$ and $\mathrm{pH} 4.54$, respectively. IPTG was eluted at $2.87 \mathrm{~min}$, with an oxygen peak observed at about $3.1 \mathrm{~min}$. Dissolved $\mathrm{O}_{2}$ was found in both mobile phases, but the presence of $\mathrm{O}_{2}$ in the $\mathrm{pH} 5.45$ solvent is a little later than that of $\mathrm{pH} 4.54$ solvent. Consequently, the IPTG standard peak can be easily separated and determined at this $\mathrm{pH}$ value [20].

\section{Range of linearity and limits of detection}

The linear dynamic range of the IC-PED response for IPTG was determined. The response was linear over the range from 0.1 to 10 $\mathrm{mg} / \mathrm{L}$. The regression equation was $\mathrm{Y}=0.0180 \mathrm{X}+0.1267$ where $\mathrm{Y}$ is the integral area, $\mathrm{X}$ is the concentration $(\mathrm{mg} / \mathrm{L})$, and the correlation coefficient $(r)=0.9972(n=7)$. The limit of detection $(S / N=3)$ for $25 \mu \mathrm{L}$ injections of IPTG was estimated to be $1 \mu \mathrm{g} / \mathrm{L}(0.1 \mathrm{pmol})$.

\section{Application}

The optimized method was utilized to determine IPTG in rhGH samples produced by Zhangjiang Bio-Tech Co. Ltd Shanghai, China. Chromatograms of rhGH products are presented in Figure 5 obtained with $0.01 \mathrm{~mol} / \mathrm{L}$ pH $5.45 \mathrm{NaOAc}$ buffer/ACN (90:10, v/v). The method of standard addition was performed to assay the recoveries of IPTG and the results were summarized in Table 1. Good separation and high sensitivity for IPTG were obtained. 
Citation: Wang L, Lin B (2017) Determination of IPTG in Recombinant Human Growth Hormone with lon Chromatography and Pulsed

\section{Conclusion}

Pulsed electrochemical detection following IC allows for the simple and direct detection of numerous sulfur-containing compounds. In agreement with the past efforts, IPAD is well-suited for the detection of thiocompounds such as IPTG. The IPAD waveform, which needs only to be optimized for a particular $\mathrm{pH}$, allows for the direct detection of the analytes at low levels with superior limits of detection. Through the use of an acidic mobile phase $(\mathrm{pH}=5.45)$ under reversed-phase conditions, selectivity is achieved for IPTG. The reported method shows good stability and reproducibility. The linear ranges cover over three orders of magnitude and the limits of detection can reach $1 \mu \mathrm{g} / \mathrm{L}$ $(0.1 \mathrm{pmol})$ for IPTG. The system performance was excellent for the rapid determination of rhGH samples. The high selectivity and good sensitivity of this approach assures that the matrix components of the assay do not interfere with the determination.

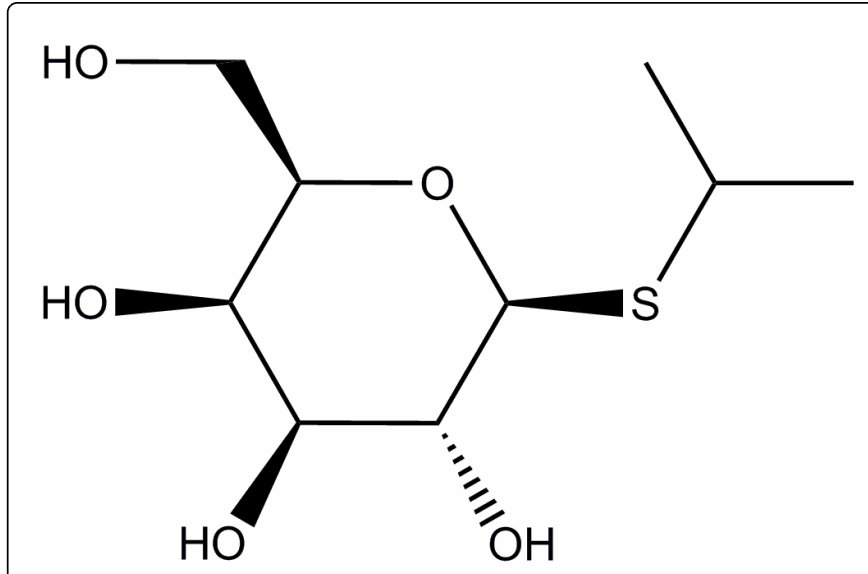

Figure 1: Structural formula of isopropyl-D-thiogalactopyranoside.

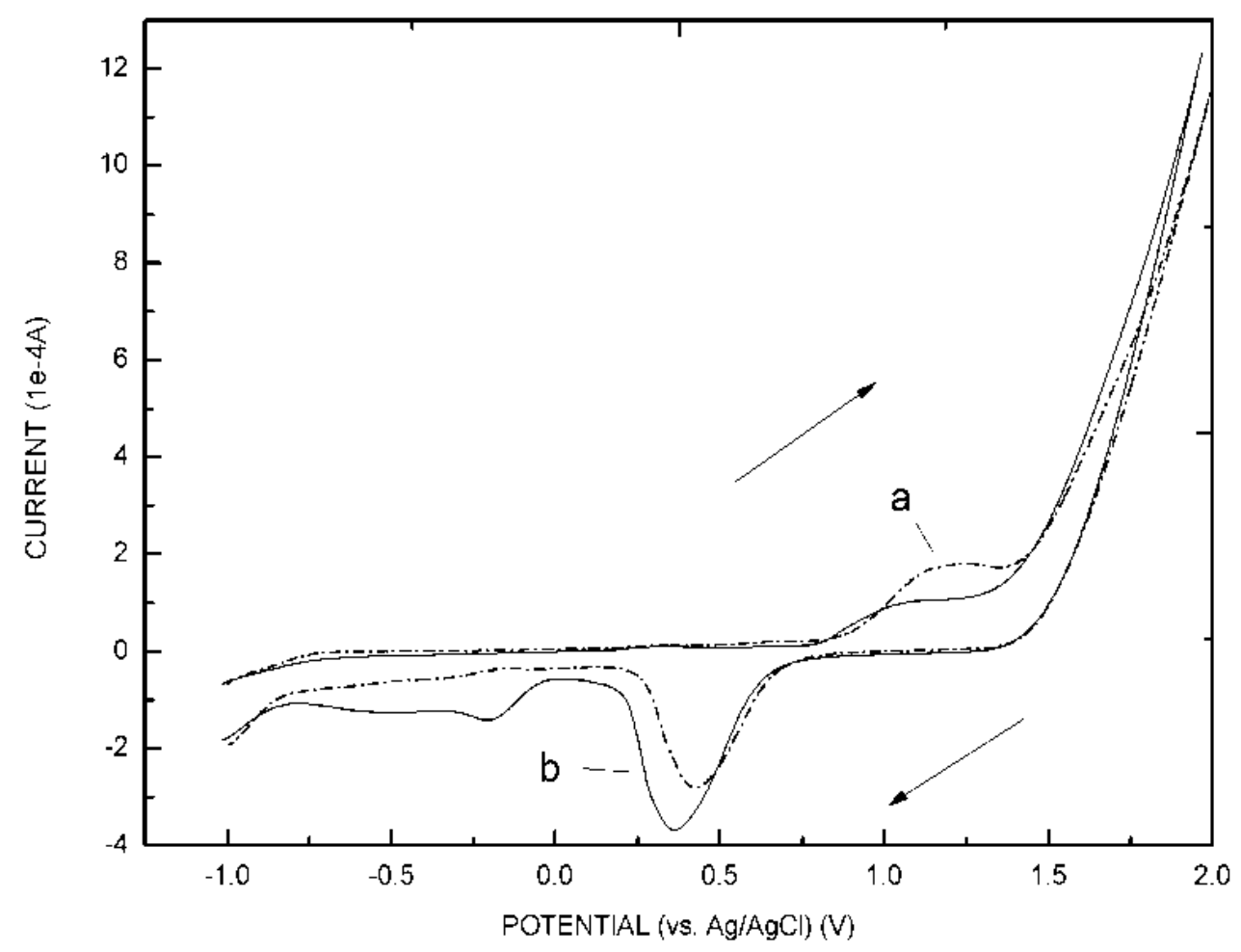

Figure 2: Voltammetric response for $100 \mathrm{mg} / \mathrm{L}$ IPTG in $0.01 \mathrm{~mol} / \mathrm{L} \mathrm{pH} 5.45 \mathrm{NaOAc} / \mathrm{ACN}(90: 10$, v/v) at $3 \mathrm{mmAu}$ RDE. Degassed in the (b) absence and (a) presence of $100 \mathrm{mg} / \mathrm{L}$ IPTG. The forward scan $(\nearrow)$, the reverse scan $(\measuredangle)$; Scan rate: $100 \mathrm{mV} / \mathrm{s}$. 
Citation: Wang L, Lin B (2017) Determination of IPTG in Recombinant Human Growth Hormone with lon Chromatography and Pulsed

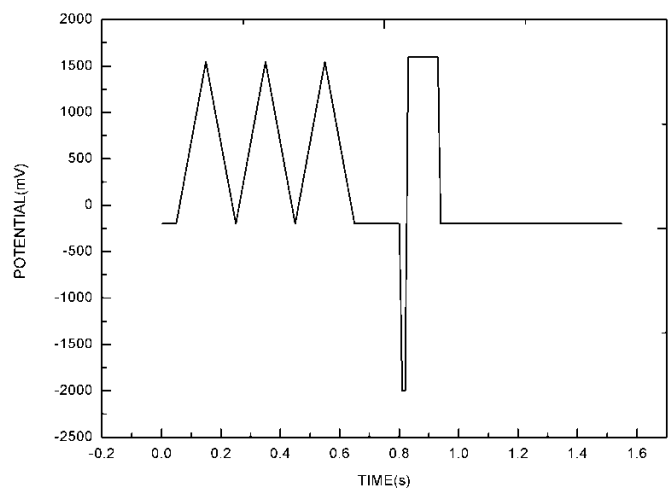

Figure 3: Waveform of the IPAD.
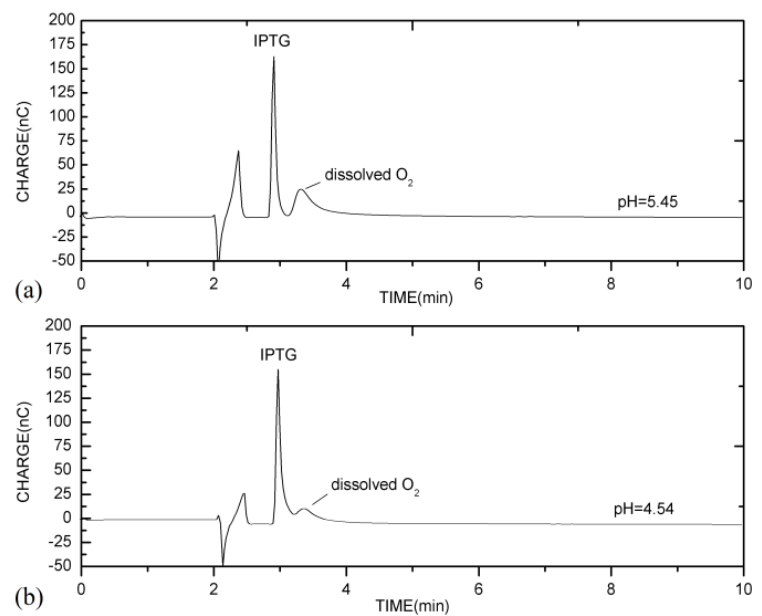

Figure 4: Chromatograms of IPTG standard in $0.01 \mathrm{~mol} / \mathrm{L} \mathrm{NaOAc}$ buffers at (a) $\mathrm{pH} 5.45$ and (b) $\mathrm{pH} 4.54$.

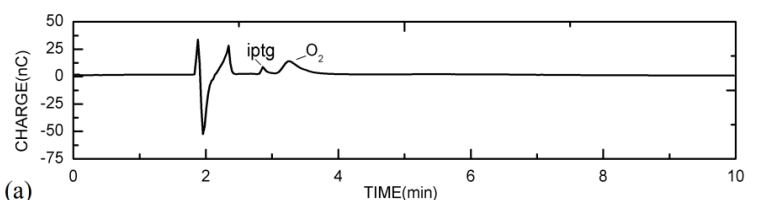

(a)
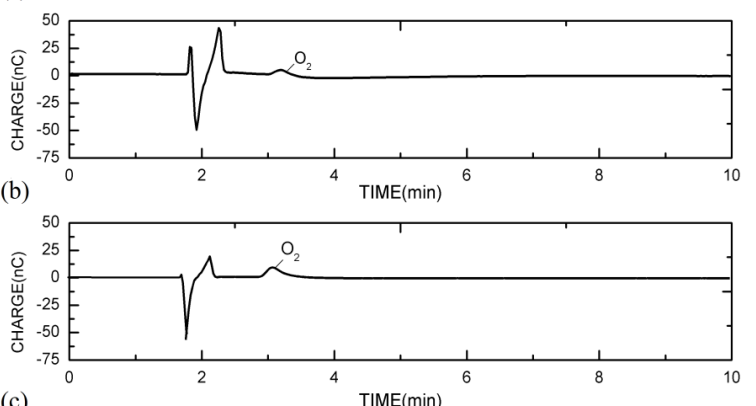

(c)

Figure 5: Chromatograms of rhGH samples. a. rhGH sample +standard; b. rhGH sample; c. blank.

\begin{tabular}{|l|l|l|l|}
\hline Background/(mg/L) & Standard addition/(mg/L) & Found/(mg/L) & $\begin{array}{l}\text { Recovery/\% } \\
\pm \text { R.S.D }\end{array}$ \\
\hline ND & 0.020 & 0.020 & $100 \pm 5$ \\
\hline ND & 0.050 & 0.051 & $102 \pm 3$ \\
\hline ND & 0.100 & 0.100 & $100 \pm 6$ \\
\hline
\end{tabular}

Table 1: Contents of IPTG in rhGH samples and the results of recovery test $(n=3)$.

\section{References}

1. Mukhija R, Rupa P, Pillai D, Garg LC (1995) High-level production and one-step purification of biologically active human growth hormone in Eescherichia coli. Gene 165: 303-306.

2. Jalalipour M, Gilani K, Tajerzadeh H, Najafabadi AR (2008) Characterization and aerodynamic evaluation of spray dried recombinant human growth hormone using protein stabilizing agents. Int J Pharm 352: 209-216

3. Freitas DS, Mero A, Pasut G (2013) Chemical and Enzymatic Site Specific PEGylation of hGH. Bioconjug Chem 24: 456-463.

4. Cai Y, Xu M, Yuan M, Liu Z, Yuan W, et al. (2014) Developments in human growth hormone preparations: sustained-release, prolonged half- 
Citation: Wang L, Lin B (2017) Determination of IPTG in Recombinant Human Growth Hormone with lon Chromatography and Pulsed Electrochemical Detection. Mod Chem appl 5: 232. doi:10.4172/2329-6798.1000232

Page 5 of 5

life, novel injection devices, and alternative delivery routes. Int Nanomedicine 9: 3527-3538.

5. Teich A, Lin HY, Andersson L, Meyer S (1998) Amplification of ColE1 related plasmids in recombinant cultures of Escherichia coli after IPTG induction. J Biotechnol 64: 197-210.

6. Morris J, Jayanthi S, Langston R, Daily A, Kight A, et al. (2016) Heparinbinding peptide as a novel affinity tag for purification of recombinant proteins. Protein Expr Purif 126: 93-103.

7. Rahmen N, Fulton A, Ihling N, Magni M, Jaeger K, et al. (2015) Exchange of single amino acids at different positions of a recombinant protein affects metabolic burden in Escherichia coli. Microb Cell Fact 14: 10-18.

8. Shin NK, Kim DY, Shin CS, Hong MS, Lee J, et al. (1998) High-level production of human growth hormone in Escherichia coli by a simple recombinant process. J Biotechnol 62: 143-151.

9. Koskenkorva T, Frey AD, Kallio PT (2006) Characterization of heterologous hemoglobin and flavohaemoglobin promoter regulation in Escherichia coli. J Biotechnol 122: 161-175.

10. Kosinski MJ, Rinas U, Bailey JE (1992) Isopropyl- $\beta$-dthiogalactopyranoside influences the metabolism of Escherichia coli. Appl Microbiol Biot 36: 782-784.

11. Zhang S, Huang F, Zhao J, Wen L, Zhou F, et al. (2002) Determination of thiols in urinary sample by capillary-column liquid chromatography with amperometric detection at a carbon electrode. Talanta 58: 451-458.

12. Owens GS, LaCourse WR (1997) Pulsed electrochemical detection of thiols and disulfides following capillary electrophoresis. J Chromatogr B 695: 15-25.

13. Fernández A, Ruiz J, Caminal G (2010) Development and validation of a liquid chromatography-mass spectrometry assay for the quantitation of IPTG in E. coli fed-batch cultures. Anal Chem 82: 5728-5734.

14. Feng B, Gan Z, Hu H (2014) Optimization of sample pretreatment method for the determination of typical artificial sweeteners in soil by high performance liquid chromatography- tandem mass spectrometry. Chinese Journal of Chromatography 32: 930-935.

15. Zhang MY, Xu Y, Song GH (2016) Simultaneous determination of eight effective constituents in Naoxinqing crude drug and tablets by high performance liquid chromatography-tandem mass spectrometry. Chinese Journal of Chromatography 34: 773-777.

16. Huang F, Wu HQ, Huang XL (2016) Simultaneous determination of 17 aphrodisiac chemical drugs illegally added in health products and Chinese patent medicines by high performance liquid chromatographytandem mass spectrometry. Chinese Journal of Chromatography 4: 270-278.

17. Shi ZH, Zhang XY, Bu SJ (2012) Simultaneous extraction and determination of nine chemically synthetic anticoccidial drug multiresidues in chicken meat using high performance liquid chromatographytandem mass spectrometry. Chinese Journal of Chromatography 30: 883-888.

18. Glowacki R, Wojcik K, Bald E (2001) Facile and sensitive method for the determination of mesna in plasma by high-performance liquid chromatography with ultraviolet detection. J Chromatogr 914: 29-35.

19. Pitti C, Streel B, Ceccato A, Hubert J (2000) Quantitative analysis of Nacetylcysteine and its pharmacopeial impurities in a pharmaceutical formulation by liquid chromatography-UV detection-mass spectrometry. J Chromatogr A 896: 191-199.
20. Chassaing C, Gonin J, Wilcox CS, Wainer IW (1999) Determination of reduced and oxidized homocysteine and related thiols in plasma by thiolspecific pre-column derivatization and capillary electrophoresis with laser-induced fluorescence detection. J Chromatrogr B 735: 219-227.

21. Haj AI, Assaf P, Nassar T, Katzhendler J (2000) Determination of lipoic acid and dihydrolipoic acid in human plasma and urine by highperformance liquid chromatography with fluorimetric detection. J Chromatogr A 870: 381-388.

22. Shea TJ, Lunte SM (1993) Selective detection of free thiols by capillary electrophoresis-electrochemistry using a gold/mercury amalgam microelectrode. Anal Chem 65: 247-250.

23. Sandberg MS, Weber SG (1998) Comparison of anion-exchange and ionmodified reversed-phase liquid chromatography for the determination of S-sulfocysteine. J Chromatogr B 705: 251-259.

24. Eramo JL, Finkelstein AE, Boccazzi FO (1998) Total homocysteine levels in plasma: high-performance liquid chromatographic determination with electrochemical detection and glassy carbon electrode. J Chromatogr B 720: 205-210.

25. Modi SJ, LaCourse WR, Shansky RE (2005) Determination of thio-based additives for biopharmaceuticals by pulsed electrochemical detection following HPLC. J Pharm Biomed Anal 37: 19-25.

26. Vandeberg PJ, Kowagoe JL, Johnson DC (1992) Pulsed amperometric detection of sulfur compounds: thiourea at gold electrodes. Anal Chim Acta 260: 1-11.

27. Rocklin RD, Clarke AP, Weitzhandler M (1998) Improved Long-Term Reproducibility for Pulsed Amperometric Detection of Carbohydrates via a New Quadruple-Potential Waveform. Anal Chem 70: 1496-1501.

28. Dobberpuhl DA, Johnson DC (1995) Pulsed electrochemical detection at the ring of a ring-disk electrode applied to a study of amine adsorption at gold electrodes. Anal Chem 67: 1254-1258.

29. LaCourse WR, Owens GS (1995) Pulsed electrochemical detection of thiocompounds following microchromatographic separations. Anal Chim Acta 307: 301-309.

30. Vandeberg PJ, Johnson DC (1993) Pulsed electrochemical detection of cysteine, cystine, methionine, and glutathione at gold electrodes following their separation by liquid chromatography. Anal Chem 65: 2713-2718.

31. LaCourse WR, Dasenbrock CO (1999) Pulsed electrochemical detection of sulfur-containing antibiotics following high performance liquid chromatography. Pharm Biomed Anal 19: 239-252.

32. Neuberger GG, Johnson DC (1988) Pulsed coulometric detection with automatic rejection of background signal in surface-oxide-catalyzed anodic detections at gold electrodes in flow-through cells. Anal Chem 60: 2288-2293.

33. Johnson DC, Dobberpuhl D, Roberts R, Vandeberg P (1993) Pulsed amperometric detection of carbohydrates, amines and sulfur species in ion chromatography the current state of research. J Chromatogr A 640: 79-96.

34. Fedorowski J, LaCourse WR (2015) A review of pulsed electrochemical detection following liquid chromatography and capillary electrophoresis. Anal Chim Acta 861: 1-11. 